OPEN ACCESS

Edited by:

Hendrik Schmidt, Charité Medical University of

Berlin, Germany

Reviewed by:

André P. G. Castro,

Universidade de Lisboa, Portugal

Fangsen Cui,

Agency for Science, Technology and

Research (A*STAR), Singapore

*Correspondence:

Zhizhong Li

lizhizhongjd@163.com

Guodong Sun

sgd96@jnu.edu.cn

Yuen Huang

835010749@qq.com

tThese authors have contributed equally to this is work

Specialty section:

This article was submitted to Biomechanics,

a section of the journal

Frontiers in Bioengineering and Biotechnology

Received: 15 March 2021

Accepted: 11 June 2021

Published: 14 July 2021

Citation:

Wo J, Lv Z, Wang J, Shen K, Zhu H,

Liu Y, Huang Y, Sun G and Li Z (2021) Biomechanical Analysis of Cervical Artificial Disc Replacement Using Cervical Subtotal Discectomy Prosthesis.

Front. Bioeng. Biotechnol. 9:680769. doi: 10.3389/fbioe.2021.680769

\section{Biomechanical Analysis of Cervical Artificial Disc Replacement Using Cervical Subtotal Discectomy Prosthesis}

\author{
Jin Wo ${ }^{1+}$, Zhenjing $\mathrm{Lv}^{2 \dagger}$, Jing Wang ${ }^{3+}$, Kui Shen ${ }^{1}$, Haoran Zhu ${ }^{1}$, Yang Liu ${ }^{1}$, Yuen Huang ${ }^{4 *}$, \\ Guodong Sun ${ }^{1,5 *}$ and Zhizhong $\mathrm{Li}^{1,5,6 *}$ \\ ${ }^{1}$ Department of Orthopedics, First Affiliated Hospital, Jinan University, Guangzhou, China, ${ }^{2}$ Department of Spine \\ Orthopedics, Guangdong Hospital of Integrated Traditional Chinese and Western Medicine, Foshan, China, ${ }^{3}$ Department of \\ Neurosurgery, First Affiliated Hospital, Jinan University, Guangzhou, China, ${ }^{4}$ Department of Rehabilitation, First Affiliated \\ Hospital, Jinan University, Guangzhou, China, ${ }^{5}$ Department of Orthopedics, Fifth Affiliated Hospital, Heyuan Shenhe \\ People's Hospital, Jinan University, Heyuan, China, ${ }^{6}$ Department of Orthopedics, Heyuan People's Hospital, Heyuan \\ Affiliated Hospital of Jinan University, Heyuan, China
}

Background: Anterior cervical discectomy and fusion (ACDF) sacrifices segmental mobility, which can lead to the acceleration of adjacent segment degeneration. The challenge has promoted cervical artificial disc replacement (CADR) as a substitute for ACDF. However, CADR has revealed a series of new issues that are not found in ACDF, such as hypermobility, subsidence, and wear phenomenon. This study designed a cervical subtotal discectomy prosthesis (CSDP) consisting of a cervical disc prosthesis structure (CDP structure), cervical vertebra fixation structure (CVF structure), link structure, and locking screw, aiming to facilitate motion control and reduce subsidence. The aim of this study was to assess the biomechanics of the CSDP using finite element (FE) analysis, friction-wear test, and non-human primates implantation study.

Study Design: For the FE analysis, based on an intact $\mathrm{FE} \mathrm{C}_{2}-\mathrm{C}_{7}$ spinal model, a CSDP was implanted at $\mathrm{C}_{5}-\mathrm{C}_{6}$ to establish the CSDP FE model and compare it with the Prestige LP prosthesis (Medtronic Sofamor Danek, Minneapolis, MN, United States). The range of motion (ROM), bone-implant interface stress, and facet joint force were calculated under flexion extension, lateral bending, and axial rotation. In addition, CSDP was elevated $1 \mathrm{~mm}$ to mimic an improper implantation technique to analyze the biomechanics of CSDP errors in the FE model. Moreover, the friction-wear test was conducted in vitro to research CSDP durability and observe surface wear morphology and total wear volume. Finally, the CSDP was implanted into non-human primates, and its properties were evaluated and verified by radiology.

Results: In the FE analysis, the ROM of the CSDP FE model was close to that of the intact FE model in the operative and adjacent segments. In the operative segment, the CSDP error FE model increased ROM in flexion extension, lateral bending, and axial rotation. The maximum stress in the CSDP FE model was similar to that of the intact FE model and was located in the peripheral cortical bone region. The facet joint force changes were minimal in extension, lateral bending, and axial rotation loads in CSDP. In 
the friction-wear test, after the 150-W movement simulation, both the CVF-link-junction and the CDP-link-junction had slight wear. In the CSDP non-human primate implantation study, no subsidence, dislocation, or loosening was observed.

Conclusion: In the FE analysis, the biomechanical parameters of the CSDP FE model were relatively close to those of the intact FE model when compared with the Prestige LP FE model. In terms of CSDP error FE models, we demonstrated that the implantation position influences CSDP performance, such as ROM, bone-implant interface stress, and facet joint force. In addition, we performed a friction-wear test on the CSDP to prove its durability. Finally, CSDP studies with non-human primates have shown that the CSDP is effective.

\section{Keywords: biomechanics, cervical artificial disc replacement, finite element analysis, prosthesis, range of segmental motion, stress, facet joint}

\section{INTRODUCTION}

Anterior cervical discectomy and fusion (ACDF) has been successfully applied to obtain functional recovery in degenerative disc disease; however, the treatment requires fusing segments (Mo et al., 2015). Although clinical evidence is still not sufficient to verify that adjacent segment degeneration is caused by the fusion, it is widely recognized that the range of motion (ROM) at non-fused levels will increase inevitably when segmental motion is abolished by the fusion. The increased ROM was considered to be linked with intervertebral disc pressure and even non-fused segment degeneration (Hilibrand and Robbins, 2004; Dmitriev et al., 2005; Carrier et al., 2013). Additionally, a reoperation rate of $10 \%$ was caused by other ACDF complications, such as implantation site pain and implant-bone non-union (Zhong et al., 2016). These issues have facilitated the development of cervical artificial disc replacement (CADR) as a substitute method for ACDF.

As an alternative method, CADR preserves segmental mobility by maintaining adjacent intervertebral disc pressure and avoiding adjacent segment degeneration (Sasso et al., 2011; Pandey et al., 2017). To date, the U.S. Food and Drug Administration (FDA) has approved seven CADR devices (Nunley et al., 2018). Most of these devices have polymeron-metal or metal-on-metal designs to form ball-in-socket sliding articulation (Gandhi et al., 2015). These prostheses have produced satisfactory testing results in clinical trials. However, they also have some problems, such as subsidence, dislocation, and wear phenomenon (Di Martino et al., 2015).

Among these issues, subsidence has been one of the most commonly reported problems, with an incidence of $3-10 \%$ (Anderson and Rouleau, 2004). Moreover, reduced bone mineral density caused by overpolishing the end plate and prosthesis design-related uneven stress distribution exacerbate subsidence (Anderson and Rouleau, 2004; Thaler et al., 2013). The wear phenomenon is a physical process caused by motion across a bearing surface. In prostheses, it is associated with the formation of particular wear debris, loss of joint height, and, ultimately, joint failure. More importantly, the particulate debris will induce inflammation mediated by various cytokines. This inflammatory response can lead to pain, osteolysis, and prosthetic loosening (Anderson and Rouleau, 2004; Matge et al., 2015). Additionally, previous research has suggested that the ball-in-socket sliding articulation may induce hypermobility at the surgical level, leading to increased stress on the operative segment and facet joints (Chang et al., 2007b; Kowalczyk et al., 2011; Lee et al., 2011). This stress may play an important role in "operative segment degeneration," which is one of the major factors that may compromise the long-term results of CADR (Rundell et al., 2008). Thus, the above-mentioned problems have become the focus of CADR improvements and need to be considered when developing new artificial cervical discs.

In this study, we have designed a cervical subtotal discectomy prosthesis (CSDP), consisting of the cervical disc prosthesis structure (CDP structure), cervical vertebra fixation structure (CVF structure), link structure, and locking screw. Artificial disc designs will behave mechanically different because of the distinctiveness of each implant design. These varying designs resulted in different biomechanical alterations in the cervical spine after arthroplasty. Therefore, the purpose of this research was to estimate biomechanical patterns of CSDP at the $\mathrm{C}_{5}-\mathrm{C}_{6}$ level of the cervical spine and to analyze the underlying mechanisms.

The finite element (FE) analysis, an ideal method for research on spine biomechanics, can predict cervical biomechanical responses to different cervical artificial discs (Faizan et al., 2012). Moreover, the FE analysis has unique advantages for measuring biomechanical parameters, such as bone-implant interface stress and implant internal structure stress, which are closely related to subsidence, dislocation, and wear of an implant (Lazaro et al., 2010).

In this experiment, we analyzed and compared biomechanics of the CSDP and Prestige LP prosthesis (Medtronic Sofamor Danek, Minneapolis, MN, United States) by the FE analysis. The main biomechanical parameters included ROM, boneimplant interface stress distribution, and facet joint force. In addition, CADR complications have also been attributed to iatrogenic circumstances, for example, improper positioning of the device (Bertagnoli et al., 2005). Therefore, we moved the CSDP up $1 \mathrm{~mm}$ to simulate improper positioning of 
the device, and the biomechanics were measured by the FE analysis under the same conditions. Moreover, we conducted a friction-wear test in vitro to research CSDP durability and to understand the long-term mechanical influences of internal structure interaction. Finally, the CSDP was implanted into nonhuman primates, and its properties were evaluated and verified by radiology.
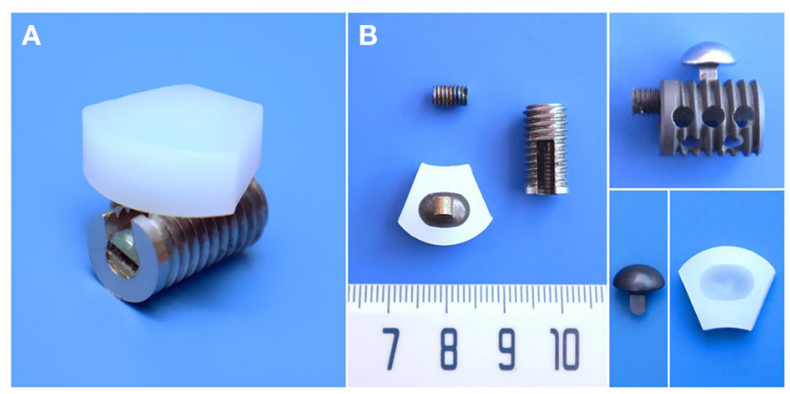

FIGURE 1 | Structural design and material specifications of cervical subtotal discectomy prosthesis (CSDP). (A) Oblique views of the assembled CSDP. (B) The CSDP consists of cervical disc prosthesis (CDP) structure, cervical vertebra fixation (CVF) structure, link structure, and locking screw. The link structure constitutes the ellipsoid-in-socket articulation with the CDP structure and is fixed on the CVF structure by the locking screw.

\section{MATERIALS AND METHODS}

\section{Design Considerations and Material Specifications of CSDP}

The CSDP itself consists of four primary components: CDP structure (ultrahigh molecular weight polyethylene, UHMWPE), CVF structure, link structure, and locking screw (titanium alloy). As an artificial cervical disc, the motion function of the CSDP depends on the articulation composed of the CDP structure and link structure. Different from ball-insocket articulation-designed artificial discs, the CSDP has an ellipsoid-in-socket articulation design to limit hypermobility. In addition to constituting the articulation of CSDP, another function of the link structure is affixing the CDP structure to the CVF structure by locking screws. The CVF structure is cylindrical with screw threads on the surface. Similar to "hemiarthroplasty," CSDP fixation depends on the CVF structure in the vertebra; therefore, the CVF structure should be implanted first in CSDP surgery. Before CVF-structure implantation, the inferior vertebra at the operative level was grooved using curettage and a high-speed burr, and the groove was placed close to the upper end plate. Then, the CVF structure was screwed into the groove for early fixation. Moreover, several tunnels, similar to a cervical fusion cage, were reserved in the CVF structure to achieve fusion after long-term implantation (Figure 1).

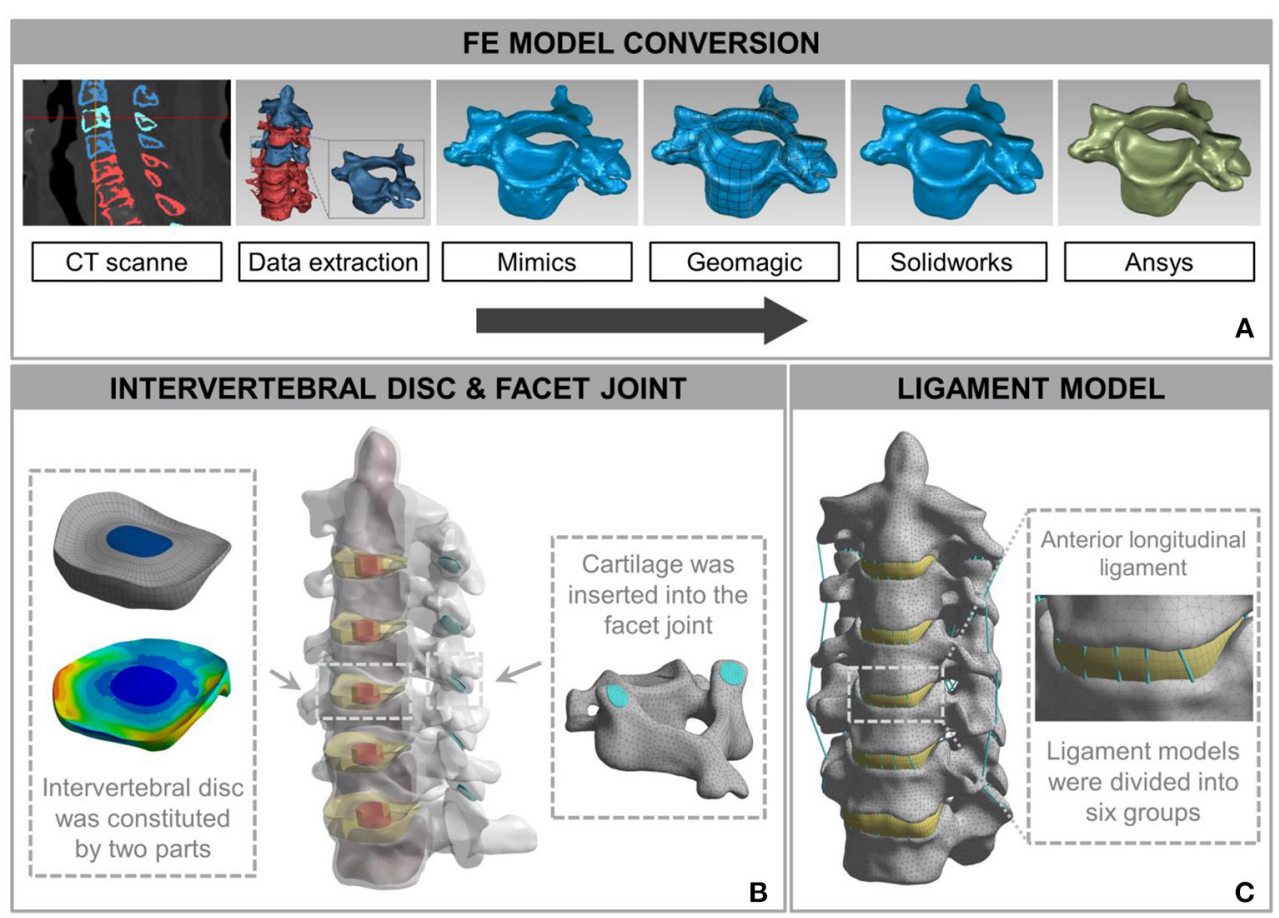

FIGURE 2 | Development and validation of intact finite element (FE) cervical spine model. (A) The conversion procedure for developing FE cervical vertebrae models included reconstructing a geometrical structure of vertebrae (Mimics 20.0), performing smooth operation (Geomagic 12), and supporting format conversion by computer-aided design (CAD) software (Solidworks 2015). Then, the output document was imported into FE software (Ansys Workbench 18.0) to build the cervical spine components. (B) A model consisting of a vertebra disc and an intervertebral disc was constructed by cartilage and intervertebral discs inserted into the facet joint and the intervertebral space. (C) The intact FE cervical spine model with ligament construction. 
TABLE 1 | Material property and mesh type of the prostheses and cervical spine components.

\begin{tabular}{|c|c|c|c|c|c|}
\hline Component & Young modulus (MPa) & Poisson ratio & Cross section area $\left(\mathrm{mm}^{2}\right)$ & Element type & References \\
\hline \multicolumn{6}{|l|}{ Bone } \\
\hline Cortical bone & $12,000.0$ & 0.29 & - & Tetrahedron & $\begin{array}{l}\text { Ng et al., 2004; Zhang et al., } \\
\text { 2006; Lee et al., } 2011\end{array}$ \\
\hline Cancellous bone & 450.0 & 0.29 & - & Tetrahedron & \\
\hline Post bone & $3,500.0$ & 0.29 & - & Tetrahedron & \\
\hline End plate & 500.0 & 0.40 & - & Tetrahedron & \\
\hline Cartilage & 10.4 & 0.40 & - & Hexahedron & \\
\hline Nucleus & 1.0 & 0.49 & - & Hexahedron & \\
\hline Annulus & 3.4 & 0.40 & - & Hexahedron & \\
\hline \multicolumn{6}{|l|}{ Ligaments } \\
\hline Anterior longitudinal & 10.0 & 0.30 & 6.0 & Link & Lee et al., 2011; Yu et al., 2016 \\
\hline Posterior longitudinal & 10.0 & 0.30 & 5.0 & Link & \\
\hline Ligamentumflavum & 1.5 & 0.30 & 5.0 & Link & \\
\hline Interspinous & 1.5 & 0.30 & 10.0 & Link & \\
\hline Supraspinous & 1.5 & 0.30 & 5.0 & Link & \\
\hline Capsular & 10.0 & 0.30 & 46.0 & Link & \\
\hline \multicolumn{6}{|l|}{ Artificial disc } \\
\hline Titanium alloy & $110,000.0$ & 0.30 & - & Tetrahedron & Lee et al., 2011; Yu et al., 2016 \\
\hline UHMWPE & $3,000.0$ & 0.30 & - & Tetrahedron & \\
\hline
\end{tabular}

\section{Finite Element Biomechanical Analysis Development of Intact FE Cervical Spine Model}

The FE model of $\mathrm{C}_{2}-\mathrm{C}_{7}$ was developed based on CT images of a healthy subject (male, age 31 years, height $175 \mathrm{~cm}$, weight $74 \mathrm{~kg}$ ) without radiographic changes in cervical vertebrae or a history of cervical disc disease. The procedure for developing the intact $\mathrm{C}_{2}-\mathrm{C}_{7} \mathrm{FE}$ cervical spine model is shown in Figure 2. Computed tomography scans of the subject were obtained at $0.5-\mathrm{mm}$ intervals. Computed tomographic images re-established the three-dimensional structure of the vertebrae by imageprocessing software (Mimics 20.0, Materialise, Leuven, Belgium) and were then executed according to the smooth operation (Geomagic 12, Geomagic, Morrisville, NC, United States). After format conversion by computer-aided design (CAD) software (Solidworks 2015, Dassault, Vélizy-Villacoublay, France), the output was imported into FE software (Ansys Workbench 18.0, Ansys, Canonsburg, PA, United States) to construct cervical vertebrae (Figure 2A). The cartilages were imported into articular processes to constitute facet joints, and the frictional coefficient was set at 0.1 . The intervertebral discs were divided into two parts: nucleus pulposus and annulus fibrosus. The FE model composed of the cervical vertebrae, facet joints, and intervertebral discs was built using the above process (Figure 2B). The ligament models contained the anterior longitudinal ligament, capsular ligament, posterior longitudinal ligament, interspinous ligament, supraspinous ligament, and ligamentum flavum, which were divided into six groups with geometrical linear contact elements utilizing tension.

The calculation time of the three meshes (mesh 1: $0.5 \mathrm{~mm}$; mesh 2: $1 \mathrm{~mm}$; and mesh 3: $1.5 \mathrm{~mm}$ ) in the same configuration of the same computer were 98,56 , and $24 \mathrm{~min}$. The differences between the tissues of mesh 1 and mesh 2 were $<1 \%$. Mesh 2 was considered to be a convergent mesh of intact FE cervical spine model. The numbers of nodes and elements in the intact FE cervical spine model were 446,263 and 226,402, respectively, which guaranteed the accuracy of calculations related to the mesh itself. The model and material properties were set based on previously published literature (Ng et al., 2004; Zhang et al., 2006; Lee et al., 2011; Yu et al., 2016). Material properties of the prostheses and the cervical spine components are presented in Table 1. Finally, we established an FE model of the intact $\mathrm{C}_{2}-\mathrm{C}_{7}$ spinal segment (Figure 2C).

For validation, the intact $\mathrm{FE}$ model was loaded in flexion extension, lateral bending, and axial rotation by imposing $1.5 \mathrm{Nm}$ on $\mathrm{C}_{2}$ with $\mathrm{C}_{7}$ firmly fixed. For this purpose, on the middle top of $\mathrm{C} 2-\mathrm{C} 7$, six distinctive measuring material points were identified. The angles that were produced by the vector connected by adjacent points before and after the simulation depicted the ROM from $\mathrm{C} 2$ to $\mathrm{C} 7$. Under respective loading situations in light of prior experiments, ROM was compared with outcomes in the literature by Pelker et al. (1991), Panjabi et al. (2001), Kubo et al. (2003) and Ng et al. (2004) aiming to evaluate the validity of the intact FE model.

\section{Development of CADR FE Model}

The CSDP and Prestige LP were modeled using actual specimen sizes and material properties available in the literature (Table 2). The Prestige LP model consisted of two titanium end plates with the upside-down dome of the superior end plate articulating with the groove of the inferior end plate, and with the frictional coefficient set at 0.2 . In order to simplify the CSDP model, three structures were constructed, namely, the CDP structure, CVF structure, and link structure. The CDP structure was made of UHMWPE, and the CVF structure and link structure were made 
TABLE 2 | ROM validation of intact FE cervical spine model.

\begin{tabular}{|c|c|c|c|c|c|c|}
\hline \multirow[t]{2}{*}{ Segment } & \multicolumn{2}{|c|}{ Flexion extension (ROM) } & \multicolumn{2}{|c|}{ Lateral bending (ROM) } & \multicolumn{2}{|c|}{ Axial rotation (ROM) } \\
\hline & Intact FE model $\left({ }^{\circ}\right)$ & Range $\left(^{\circ}\right)$ & Intact FE model $\left({ }^{\circ}\right)$ & Range $\left(^{\circ}\right)$ & Intact FE model $\left({ }^{\circ}\right)$ & Range $\left({ }^{\circ}\right)$ \\
\hline $\mathrm{C}_{2} / \mathrm{C}_{3}$ & 6.3 & $5.9-7.5$ & 4.9 & $3.4-15.4$ & 5.6 & $2.3-7.7$ \\
\hline $\mathrm{C}_{3} / \mathrm{C}_{4}$ & 7.9 & $7.3-11.5$ & 4.5 & $3.4-15.4$ & 7.8 & $2.3-13.0$ \\
\hline $\mathrm{C}_{4} / \mathrm{C}_{5}$ & 8.0 & $7.4-10.1$ & 4.2 & $3.4-15.4$ & 7.8 & $2.3-13.6$ \\
\hline $\mathrm{C}_{5} / \mathrm{C}_{6}$ & 8.4 & $7.2-9.9$ & 3.7 & $3.1-15.4$ & 5.9 & $2.3-13.8$ \\
\hline $\mathrm{C}_{6} / \mathrm{C}_{7}$ & 7.9 & $5.7-11.5$ & 3.7 & $3.4-15.4$ & 4.8 & $2.1-10.8$ \\
\hline
\end{tabular}

entirely of titanium alloy. The CVF structure and link structure were set to bond upon contact, replacing the function of the locking screw. Friction contact was also used for the ellipsoidin-socket articulation of CSDP constituted by the CDP structure and link structure, and the frictional coefficient was set at 0.08 (Figure 3A).

The two models were implanted into the $\mathrm{C}_{5}-\mathrm{C}_{6}$ segment, where $\mathrm{CADR}$ is most frequently carried out. To imitate the Prestige LP insertion, the $\mathrm{C}_{5}-\mathrm{C}_{6}$ anterior longitudinal ligament, intervertebral disc, and end plate were removed. Then, the Prestige LP model was implanted at the $\mathrm{C}_{5}-\mathrm{C}_{6}$ segment in accordance with the clinical condition. During the CSDP insertion process, first, the CVF structure was inserted, and the cylindrical bone of the $\mathrm{C}_{6}$ vertebra was removed. Following this procedure, the CDP structure was implanted, after which the anterior longitudinal ligaments, nucleus pulposus, annulus fibrosus, and $20 \%$ of the $\mathrm{C}_{6}$ end plate were removed without removing the $\mathrm{C}_{5}$ end plate. In addition, we moved the CSDP up by $1 \mathrm{~mm}$ to mimic an imprecise surgical insertion situation as a CSDP error FE model (Figure 3B). The bond upon contact condition was defined at the boneimplant interface.

By applying $1 \mathrm{Nm}$ of flexion extension, lateral bending, and axial torsion combined with a $73.6 \mathrm{~N}$ compressive follower load on $\mathrm{C}_{2}$, the intact FE, CSDP FE, Prestige LP FE, and CSDP error FE models will bend or rotate under load (Yu et al., 2016). Simultaneously, $C_{7}$ is fixed throughout the loading process. Range of motion, bone-implant interface stress distribution, and facet joint force analysis were carried out by quasistatic testing under the load conditions mentioned above to predict biomechanical patterns at the $\mathrm{C}_{5}-\mathrm{C}_{6}$ level of the cervical spine.

\section{Friction-Wear Test}

The friction-wear test detects wear on the two junctions of CSDP: the junction composed of the CVF structure and the link structure (CVF-link-junction) and the junction composed of the CDP structure and the link structure (CDP-link-junction). The experiment simulates the wear process of the two CSDP junctions after 150-W movements in simulated body fluid (SBF) and nonSBF environments, respectively. The contact stress on CVF-linkjunction was $10 \mathrm{MPa}$ and on CDP-link-junction was $5 \mathrm{MPa}$. The surface wear morphology and total wear volume were measured by the Multi-Function Tribometer (MFT-5000, Rtec, San Jose, CA, United States).

\section{CSDP Implantation in Non-human Primates}

Care and experimental procedures for non-human primates were approved by the Institutional Animal Care and Use Committee (IACUC). This study was conducted in compliance with relevant Chinese law and regulations on the management of laboratory animals promulgated by the State Science and Technology Commission. Eight male Macaca fascicularis (Huazhen Biotechnology, Guangzhou, China), 9.2-12.1 years and $9.5-10.2 \mathrm{~kg}$, were fed in an indoor facility accredited by the Association for Assessment and Accreditation of Laboratory Animal Care International. The animals were housed in individual stainless-steel cages in a specific room where an environmental temperature of $21-25^{\circ} \mathrm{C}$ and a relative humidity range of $40-60 \%$ were maintained. Although individually housed, the animals were provided continuous auditory, visual, and olfactory contact with neighboring conspecifics. In addition to the standard non-human primate diet, water and fresh fruits were available ad libitum. Small amounts of primate treat and various cage-enrichment devices were supplied.

Prior to the surgery, each animal was sedated with ketamine $(6 \mathrm{mg} / \mathrm{kg}$ ) followed by endotracheal intubation and general anesthesia using $1.5 \%$ isoflurane. The neck area was shaved with razors and prepared with iodophor. The surgery was performed using an aseptic technique. The anterior approach to the cervical spine was adapted to the non-human primate model through a right-sided longitudinal incision (Figure 4A). Once the anterior cervical vertebral elements were exposed, the $\mathrm{C}_{5}-\mathrm{C}_{6}$ intervertebral disc was identified by $\mathrm{x}$-ray, and a CSDP implantation surgery was performed. First, the $\mathrm{C}_{6}$ vertebral body was grooved using curettage and a high-speed burr with the groove positioned close to the $\mathrm{C}_{6}$ upper end plate. The CVF structure was then implanted at the $\mathrm{C}_{6}$ groove. Second, the cartilage of the vertebral end plates was preserved, and the annulus and nucleus pulposus were removed. Finally, the CDP structure and link structure were implanted at $\mathrm{C}_{5}$ $\mathrm{C}_{6}$ and were fixed on the CVF structure by the lock screw (Figure 4B). The incision was sutured using layers, and the animals were returned to their home cages after recovery from anesthesia.

To prevent postoperative infection, the animals were treated with cefotaxime sodium (50 $\mathrm{mg} / \mathrm{kg}$ IM, twice a day for 3 days). To alleviate acute postoperative pain, the animals were treated with rotundine ( $3 \mathrm{mg} / \mathrm{kg} \mathrm{IM}$, two times a day for 3 days). The observation was carried out using a CT scanner (Siemens, 


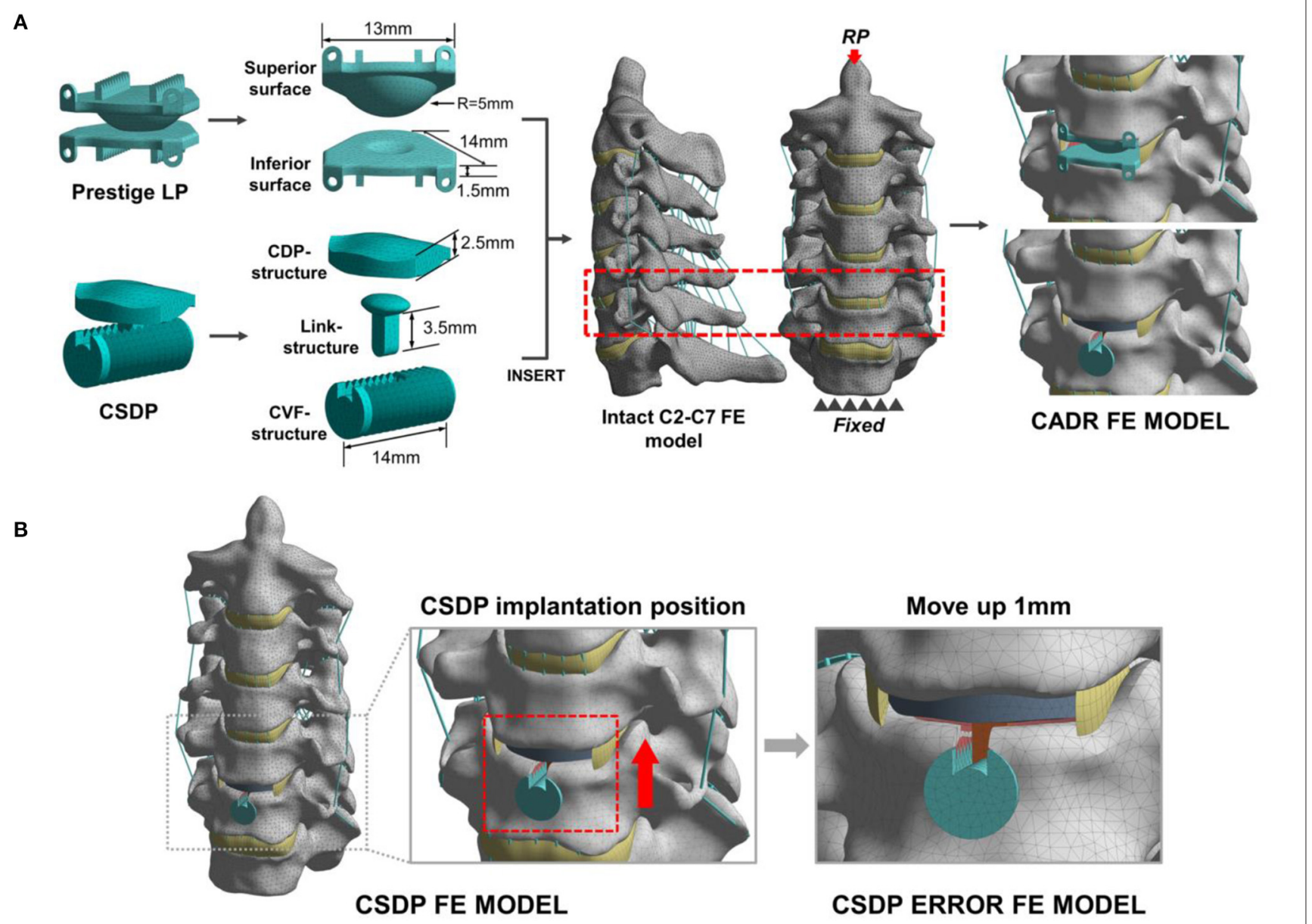

FIGURE 3 | Development and experimental conditions of the cervical artificial disc replacement (CADR) FE model. (A) The Prestige LP finite element (FE) model was composed of superior surface and inferior surface structures. The cervical subtotal discectomy prosthesis (CSDP) FE model was divided into three parts: cervical disc prosthesis (CDP) structure, cervical vertebra fixation (CVF) structure, and link structure. The Prestige LP and CSDP FE models were implanted at $\mathrm{C}_{5}$ - $\mathrm{C}_{6}$. (B) The CSDP was moved up by $1 \mathrm{~mm}$ to simulate an imprecise surgical insertion situation as a CSDP error FE model.

Munich, Germany) and a 2.0 MRI scanner (Siemens, Munich, Germany) 1 month before surgery and 1 year after surgery.

\section{RESULTS}

\section{Validation of Intact FE Cervical Spine Model}

In the FE analysis, ROM outputs acquired from the intact FE model that we constructed were compared with data from previous experiments to estimate the validity of the model (Penning, 1978; Panjabi et al., 1986, 2001; Penning and Wilmink, 1987; Moroney et al., 1988; Mimura et al., 1989; Pelker et al., 1991; Holmes et al., 1994; Lai et al., 1994; Clausen et al., 1997; Kubo et al., 2003). Range of motion at each segment in the model was all in the range of results observed in previous experimental studies, although the segmental ROM for lateral bending was near the lower bound of the range given in previous experimental studies (Figure 5 and Table 2). Based on these results, we demonstrated the validity of the intact FE cervical spine model.

\section{Range of Motion of Intact FE Cervical Spine Model and CADR FE Models} Flexion-Extension Load

Under the follower load of $73.6 \mathrm{~N}$ and the flexion-extension load of $1 \mathrm{Nm}, \mathrm{ROM}$ in CSDP and Prestige LP FE models was $28.89^{\circ}$ and $31.84^{\circ}$, respectively. Compared with $29.59^{\circ}$ in the intact FE model, ROM was decreased by $2.37 \%$ in the CSDP FE model and increased by $7.6 \%$ in the Prestige LP FE model. Although ROM in flexion extension at the $\mathrm{C}_{5}-\mathrm{C}_{6}$ segment increased by $17.76 \%$ in the case of the Prestige LP FE model, the CSDP FE model showed a decrease of $6.57 \%$ when contrasted with the intact FE model. The ratio of $\mathrm{C}_{5}-\mathrm{C}_{6}$ and $\mathrm{C}_{2}-\mathrm{C}_{7}$ ROM was $18.21 \%$ for the CSDP model and $20.82 \%$ for the Prestige LP FE model.

\section{Lateral Bending Load}

As in the flexion-extension load, no significant differences were found in the intact segments between the intact FE model and the CADR model in the lateral bending load. However, ROM of the $\mathrm{C}_{5}-\mathrm{C}_{6}$ level was $21.4 \%$ higher 

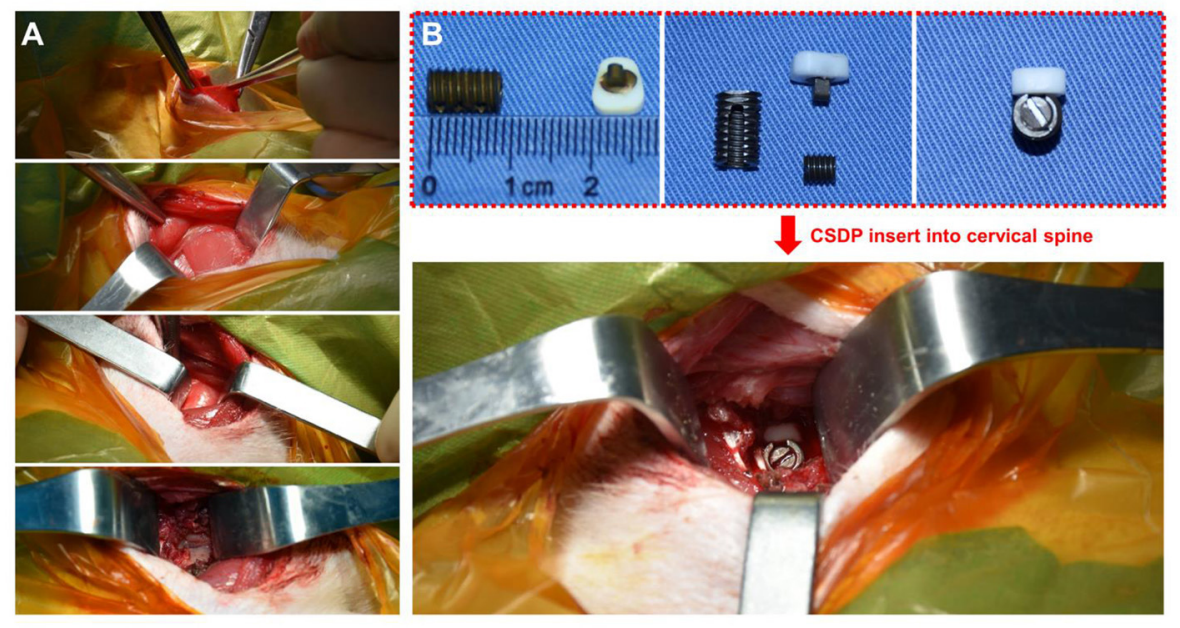

FIGURE 4 | Non-human primate cervical subtotal discectomy prosthesis (CSDP) implantation surgery. (A) After separating the skin, the platysma was cut with an electric knife. Then, the envelope fascia was sharply separated until the sternocleidomastoid muscle was seen. The sternocleidomastoid muscle was separated from the scapulohyoid muscle. Finally, the vertebral body was exposed by peeling off the longuscolli. (B) The size of the CSDP was modified based on the cervical spine anatomy of the non-human primates before implantation.

in the Prestige LP FE model and $0.6 \%$ lower in CSDP FE model compared with the intact $\mathrm{FE}$ model. The ratio of the $\mathrm{C}_{5}-\mathrm{C}_{6}$ ROM with respect to $\mathrm{C}_{2}-\mathrm{C}_{7}$ in the Prestige LP FE model and CSDP FE model was 22.52 and $19.96 \%$, respectively.

\section{Axial Rotation Load}

Under axial rotation load, no significant differences were found in the intact segments between the intact FE and CADR models. Compared with $14.6^{\circ}$ in the intact FE model, ROM in the Prestige LP FE model increased by $12.53 \%$ and decreased by $0.96 \%$ in the CSDP FE model. Range of motion at the $\mathrm{C}_{5}-\mathrm{C}_{6}$ level was $35.85 \%$ higher in the Prestige LP FE model and 5.03\% lower in the CSDP FE model when compared with the intact FE model. The ratio of the $\mathrm{C}_{5}-\mathrm{C}_{6} \mathrm{ROM}$ with respect to $\mathrm{C}_{2}-\mathrm{C}_{7}$ in the Prestige LP and CSDP FE models was 26.29 and $20.89 \%$, respectively, and differed from the $21.78 \%$ in the intact FE model (Figure 6).

\section{Stress Analysis of Intact FE Cervical Spine Model and CADR FE Models Von Mises Stress}

The Von Mises stress on the bone-implant interface in CADR FE models in flexion, extension, lateral bending, and axial rotation is shown in Figure 7A. Maximum stress on the inferior surface in the intact, Prestige LP, and CSDP-CDP-structure FE models was higher than that on the superior surface of these models (Figure 7B). Stress was concentrated in the central region in the Prestige LP FE model, and the average stress was much higher than in the CSDP-CDP structure and intact FE models. The maximum stress in the Prestige LP FE model was 18.839 $\mathrm{MPa}$, observed in axial rotation loading. In addition, maximum stress was 3.267 and $9.464 \mathrm{MPa}$ in the intact and CSDP-CDP

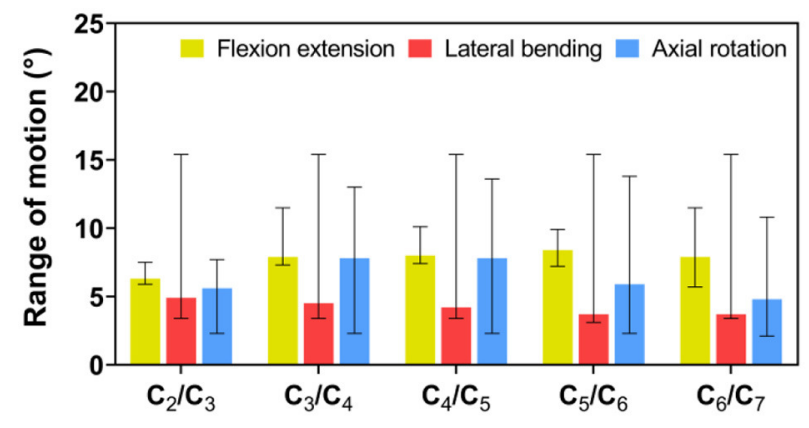

FIGURE 5 | Validation of intact finite element (FE) cervical spine model. Range of motion (ROM) outputs obtained from the intact FE model were compared with the literature data to assess the validity of the model. ROM at each segment in the intact FE model was entirely in the range of literature results.

structure FE models, respectively. The stress distribution of the CSDP-CDP structure FE model showed a trend similar to that of the intact FE model, which was located in the peripheral region but had relatively higher stress than in the intact FE model.

For the CSDP-CVF structure, maximum stress observed in flexion loading was $11.351 \mathrm{MPa}$ and was nearer to the location of the link structure, instead of the bottom; however, in flexion, the corresponding maximum stress was $18.174 \mathrm{MPa}$ for the Prestige LP FE model (Figure 8).

\section{Facet Joint Force}

The outputs of facet joint forces are presented in Figure 9. Under the flexion load, the facet joint was in an extended position, and the pressure value was not measured. In extension loading, the facet joint force increased by $167.95 \%$ in the 

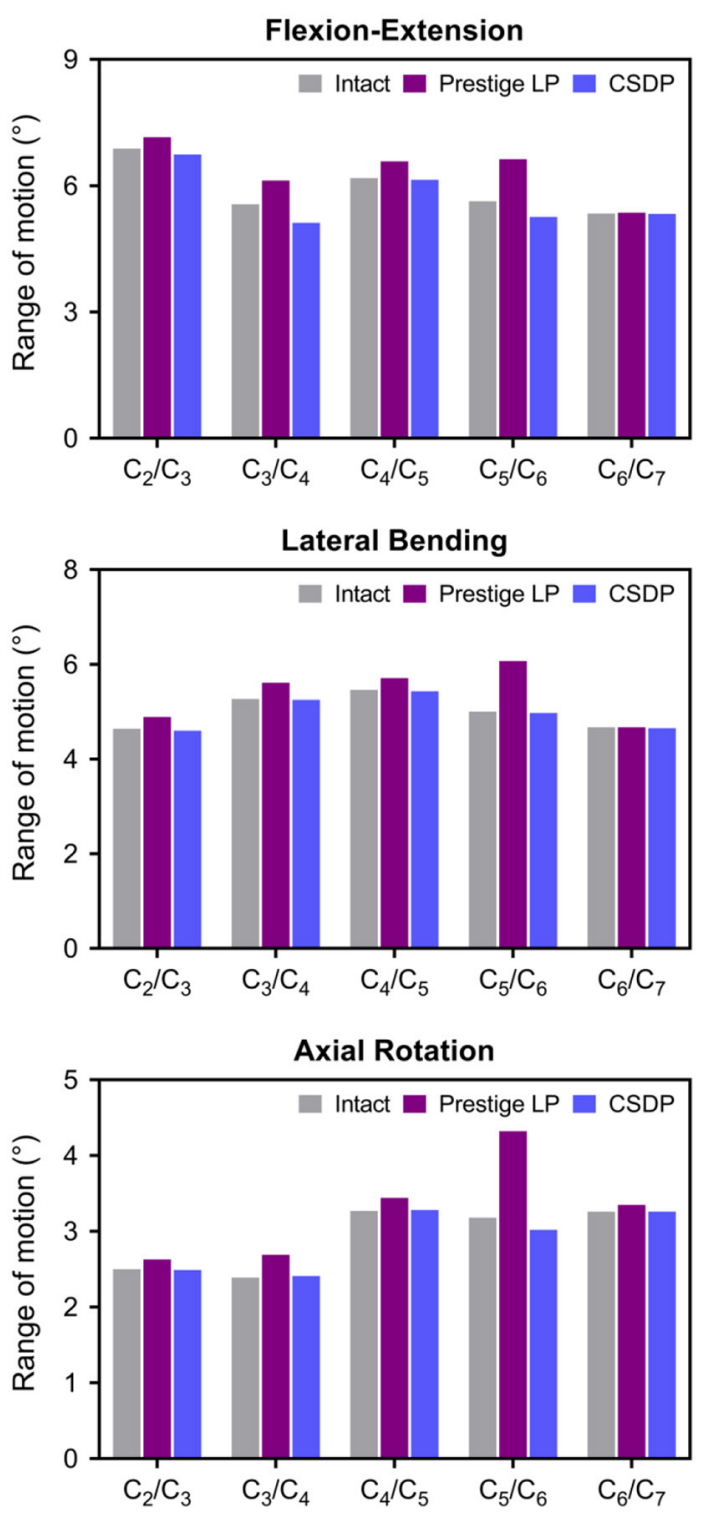

FIGURE 6 | Range of motion (ROM) of intact finite element (FE) cervical spine model and cervical artificial disc replacement (CADR) FE models. In three loads, no significant differences were found at the $\mathrm{C}_{5}-\mathrm{C}_{6}$ level and other segments between the intact FE and cervical subtotal discectomy prosthesis (CSDP) FE models. ROM at the $\mathrm{C}_{5}-\mathrm{C}_{6}$ level was higher in the Prestige LP FE model than in the intact and CSDP FE models.

Prestige LP relative to the intact FE model, while the value did not increase extremely in the CSDP FE model. The facet joints force in the lateral bending load within all CADR FE models was higher than in the intact FE model. The variation of lateral bending facet joint force in the Prestige LP and CSDP FE models was 295.13 and $2.86 \%$ of the intact value, respectively. Contrasted with the intact FE model in axial rotation, the maximum increase in facet force was $111.35 \%$ with the Prestige LP, whereas it was $0.47 \%$ with the CSDP FE model.

\section{Biomechanical Analysis of CSDP Error FE Model}

Range of Motion of CSDP Error FE Model

The results showed that ROM at $\mathrm{C}_{2}-\mathrm{C}_{7}$ increased by replacement with the CSDP error FE model, relative to the CSDP FE model. The CSDP error FE model had a significant influence on ROM in axial rotation but not in flexion extension and lateral bending. At the operative segment, with respect to the CSDP FE model, the CSDP error FE model produced a small increase of 21.67 and $16.5 \%$ ROM in flexion extension and lateral bending, respectively, while there was a $36.09 \%$ increase in axial rotation. Nevertheless, the Prestige LP FE model was more affected than the CSDP error FE model in ROM. When the CSDP error FE model was compared with the Prestige LP FE model, small decreases of $3.59,4.84$, and $5.11 \%$ were observed in flexion extension, lateral bending, and axial rotation, respectively (Figure 10A).

\section{Von Mises Stress of CSDP Error FE Model}

The Von Mises stress on the bone-implant interface of the CSDP error FE model was significantly greater than that in the CSDP FE model. Maximum stress was $9.464 \mathrm{MPa}$ in the CSDP FE model, while in lateral bending it had a value of $13.057 \mathrm{MPa}$ in the CSDP error FE model. Different from the CSDP FE model, the stress distribution of the CSDP error-CDP-structure FE model was observed in the CDP-structure central region and was significantly higher (Figure 10B). The stress sustained by the CSDP error-CVF-structure FE model was still found at the link structure, with the maximum being 16.631 MPa (Figure 10C).

\section{Facet Joint Force of CSDP Error FE Model}

The maximum stresses on facet joints in the CSDP error FE model were observed during axial rotation. Moreover, in the FE models of intact and CSDP, stress was also observed in axial rotation (Figure 10D). Although the CSDP error FE model produced higher facet-joint force than the CSDP did, the maximum facet joint force in the Prestige LP FE model was greater in all CADR FE models.

\section{Friction-Wear Test}

The results of CVF-link-junction and CDP-link-junction in the SBF and non-SBF environments after 150-W movement simulation are shown in Figure 11. In SBF, the CVF-linkjunction and CDP-link-junction have slight wear. Especially in the CVF-link-junction, the total wear volume is much lower in SBF than in non-SBF. For the wear morphology cross-section observation of the CDP-link-junction, the wear depth was only approximately $5 \mu \mathrm{m}$ in the SBF, which is lower than the $20 \mu \mathrm{m}$ in the non-SBF.

\section{Radiological Observation of CSDP in Non-human Primates}

Figure 12 shows the CT and MRI scans 1 month before and 1 year after CSDP implantation in non-human primates. CT showed that after 1 year, CSDP subsidence, dislocation, and loosening were not observed. In addition, 1 year after CSDP implantation, the inside of the CVF structure was filled with 


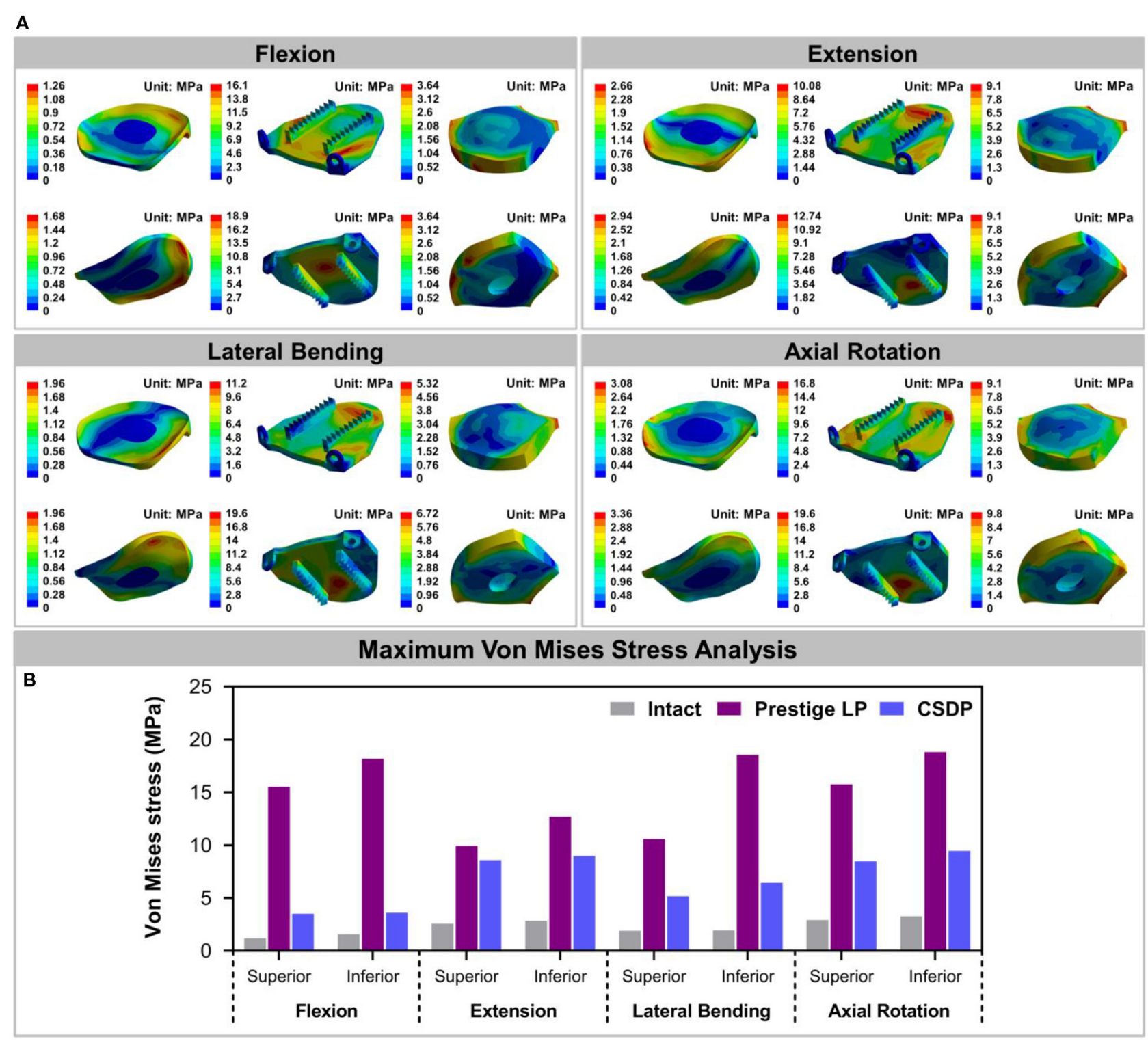

FIGURE 7 | Stress analysis of the intact finite element (FE) cervical spine model and cervical artificial disc replacement (CADR) FE models. (A) The Von Mises stress can be observed, including intact, Prestige LP, and cervical subtotal discectomy prosthesis-cervical disc prosthesis (CSDP-CDP) structure FE models in flexion, extension, lateral bending, and axial rotation loads. Stress of the Prestige LP FE model, distributed in the central region, was much higher than that of the CDP structure FE and intact FE models. Stress distribution of the CSDP-CDP structure FE model was similar to that of the intact FE model, located in the peripheral region. (B) Maximum Von Mises stress analysis of the intact, Prestige LP, and CSDP-CDP structure FE models.

the trabecular bone, and the CVF structure had undergone intravertebral fusion. Based on the MRI result, no spinal cord edema, degeneration of the adjacent intervertebral disc, or inflammation of the surrounding vertebral body was observed in the surgical segment.

\section{DISCUSSION}

Cervical artificial disc replacement aims to prevent adjacent segment degeneration by restoring intervertebral disc mobility in degenerative segmental motion. The Prestige LP prosthesis was chosen because of its current global popularity and because it is similar to most ball-in-socket sliding articulations used today (Choi et al., 2020). The Prestige LP is an open two-piece, semi-constrained design with metal-on-metal ball-in-socket articulation. The CSDP is an open four-piece, semi-constrained design with polymer-on-metal ellipsoid-in-socket articulation. Biomechanical studies have shown that ball-in-socket sliding articulation may not substantially control motion and may cause hypermobility at the surgical level (Kowalczyk et al., 2011). 
A

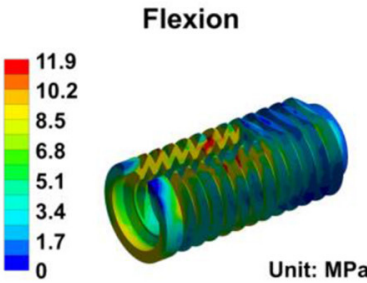

Lateral Bending

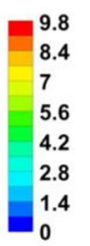

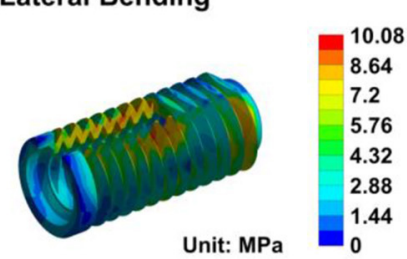

Extension
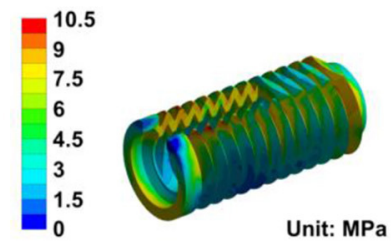

Unit: MPa

Axial Rotation

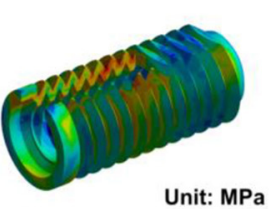

B

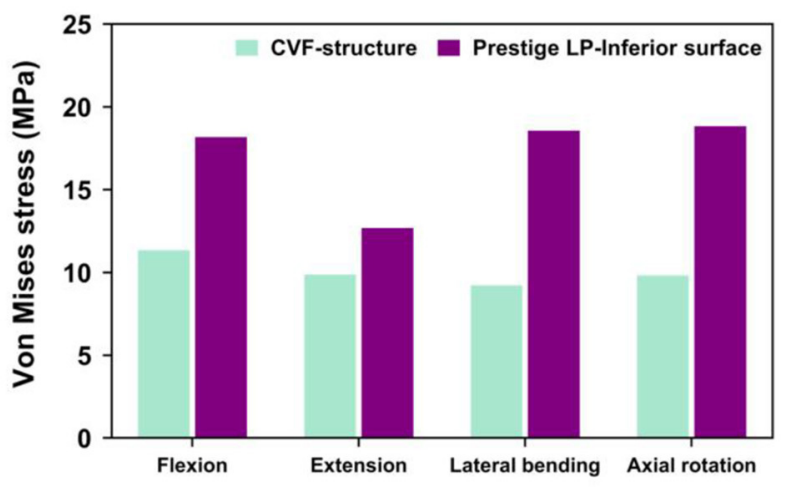

FIGURE 8 | Stress analysis of cervical subtotal discectomy prosthesis-cervical vertebra fixation (CSDP-CVF) structure. (A) Maximum stress for the CSDP-CVF structure finite element (FE) model, located nearby the link structure, instead of the bottom. (B) Maximum Von Mises stress analysis of CSDP-CVF structure FE models. Maximum stress in the CVF structure was less than that of the Prestige LP inferior surface in all loads.

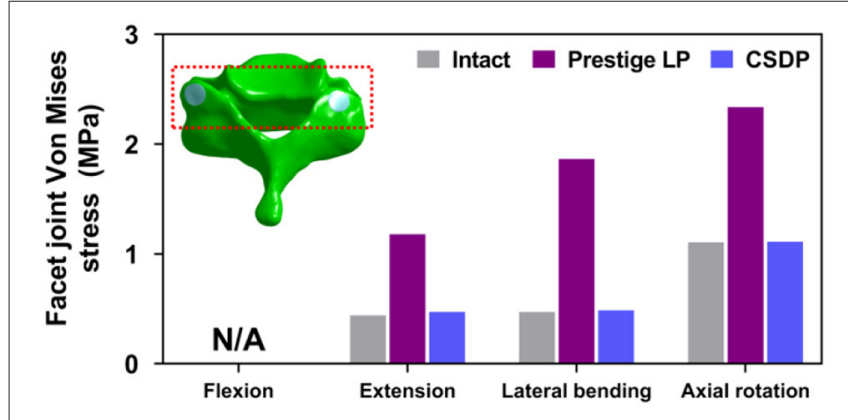

FIGURE 9 | Facet joint force analysis of the cervical subtotal discectomy prosthesis (CSDP) finite element (FE) model.

Hypermobility was a direct negative factor that increases strain in implanted segments and facet joints. Under the hypermobility condition, increasing the load through the capsular ligament during physiological situations and CADR sliding articulation configuration would alter the load transmit mode at the surgical segment. In this study, ROM distribution through $\mathrm{C}_{2}-\mathrm{C}_{7}$ segments in the CSDP FE model was almost similar to that in the intact FE model, whereas it had changed in the Prestige LP FE model. Although spinal motion in the implanted site was preserved in the Prestige LP FE model, ROM increased by 17$35 \%$ compared with the intact FE model, possibly because of a hypermobility condition. In previous studies, similar results have suggested that a significantly increased ROM at the operative segment was found after replacement with the Prestige model (Chang et al., 2007b). The coincidental result of this study and previous in vivo research confirmed this conclusion. As for the CSDP error FE model, $\mathrm{C}_{5}-\mathrm{C}_{6} \mathrm{ROM}$ was significantly greater than that in the intact and CSDP FE models regardless of motion loads.
However, the Prestige LP model generated a greater increase in $\mathrm{C}_{5}-\mathrm{C}_{6} \mathrm{ROM}$ than the CSDP error FE model did in both groups.

Subsidence and dislocation are problems that may result from intrinsic design flaws of the devices. The subsidence tendency is associated with interfacial stress increases, leading to a high boneimplant interface stress situation (Lin et al., 2009). Therefore, bone-implant interface stress may dissipate evenly in prostheses rather than in concentrated areas (Anderson and Rouleau, 2004). The stress distribution of the Prestige LP model was uneven and mostly focused on central and posterior regions; the CSDP-CDP structure FE model was similar to the intact FE model located in the peripheral cortical bone region. Moreover, the maximum stress on the superior and inferior surfaces of the Prestige LP FE model was higher compared with the CSDP FE model. It is generally acknowledged that subsidence is most often caused by improper device design that affects end plate preparation and stress distribution; however, a decrease in bone quality can also lead to subsidence (Bertagnoli et al., 2005). Bone resection may affect the structural integrity of end plates, resulting in decreased end plate bone quality. Because of the structural design of the CSDP, the $\mathrm{C}_{5}$ end plate could be saved and, therefore, decrease the risk of subsidence during operation.

The anchorage structure of the prosthesis also determines the propensity for subsidence. The potential of an artificial disc to generate interface resorption and subsequent subsidence depends on a variety of biomechanical factors that can be expressed in terms of relative movement between bone and implant at the interface (Weinans et al., 1993). Stress distribution on the surface of the anchorage structure may reflect trends in load transfer and relative movement. Similar to biomechanical disruption of the bone-implant interface of an acetabular cup in total hip replacement, micromotion can also be intensified with the displacement of the anchorage structure relative to vertebral bodies during repetitive loading. The results of stress analysis showed that the CSDP-CVF structure dissipated stress more 


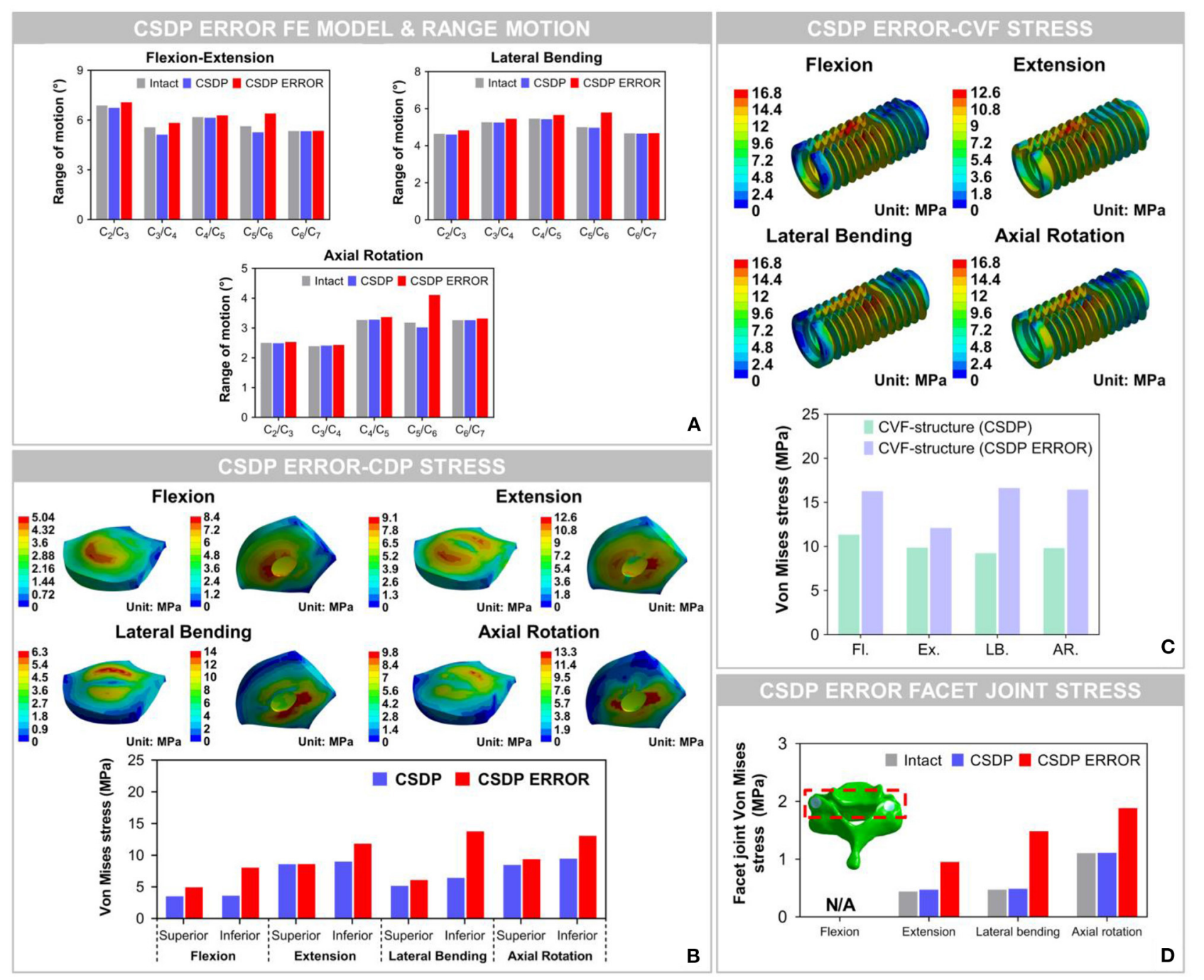

FIGURE 10 | Biomechanical analysis of the cervical subtotal discectomy prosthesis (CSDP) error finite element (FE) model. (A) The results illustrated that range of motion (ROM) increased at the $\mathrm{C}_{5}-\mathrm{C}_{6}$ level with CSDP error FE model replacement, and the CSDP error FE model had a greater effect on ROM in axial rotation than in flexion extension and lateral bending. (B) After the CSDP FE model was replaced with the CSDP error model, stress was concentrated in the central region of the CSDP error-CDP-structure FE model. (C) Stress sustained by the CSDP error-CVF-structure FE model was higher than that by the CSDP-CVF-structure FE model, yet still similar to that by the CSDP FE model. (D) Facet joint force within the CSDP error FE model was higher than that in the intact and CSDP FE models. Maximum facet joint force in the CSDP error FE model was observed during axial rotation.

evenly to provide physiological bonding at the bone-implant interface. With the Prestige LP FE model, high bone-implant interface stress occurred at the posterior flanges on the inferior surface, producing maximum stress at $18.839 \mathrm{MPa}$.

Device wear and deterioration can occur at any interface, most commonly at the bearing surfaces but also at the host-implant or implant-implant interfaces. Wear production varies, depending on the material used and mechanisms of biomechanical stress applied to the implant. The anchorage structure is indispensable in preventing the migration of the prosthesis; however, stress located in connection with various CSDP structures, especially at the junction of the link structure and CVF structure, is high. In the $\mathrm{FE}$ analysis, the maximum stress was observed at the
CVF-link-junction. Although the link structure is attached to the CVF structure by a locking screw, it still allows micromovements. It has been reported that high-stress distribution may increase the risk of wear (Lee et al., 2016). In addition, the movement of the CSDP depends on the joint CDP structure and link structure, which will also cause wear phenomena in the long term. Therefore, we carried out a friction-wear test on these joint structures. In the SBF environment, the surface wear morphology and wear volume of these joint structures illustrated that CSDP has a long-term life. Conversely, the FE analysis showed that the stress on joint interfaces increased in the CSDP error model. Although the stress in the CSDP errorCDP structure FE model was less than the corresponding yield 
A
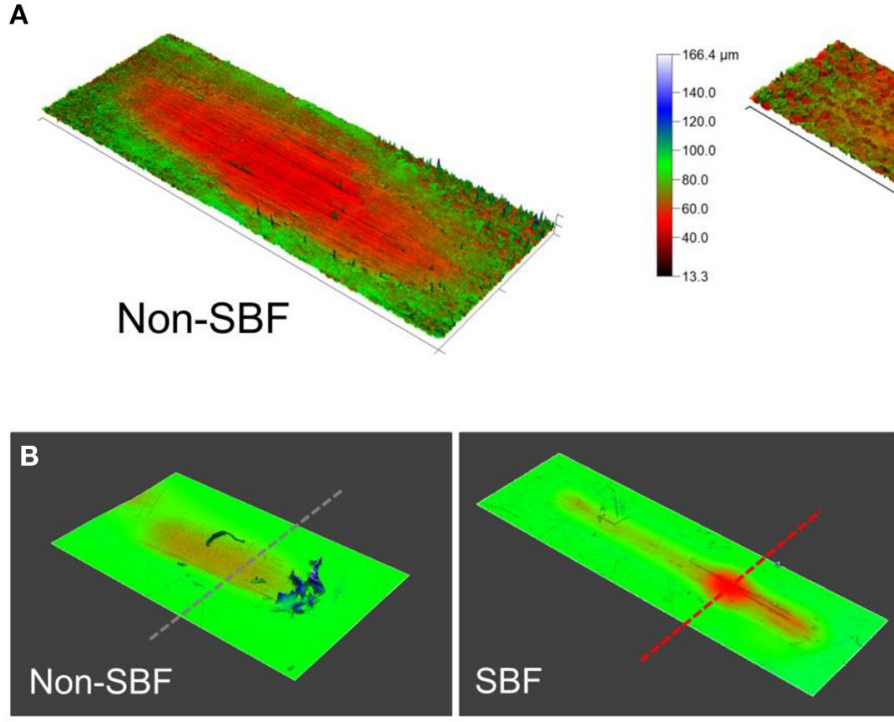

Cross section

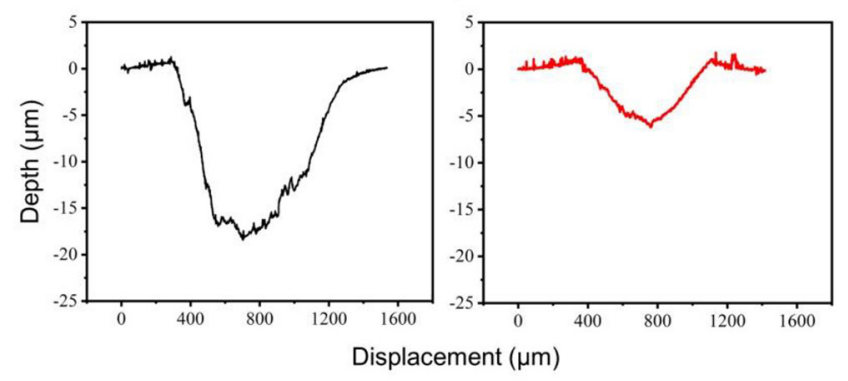

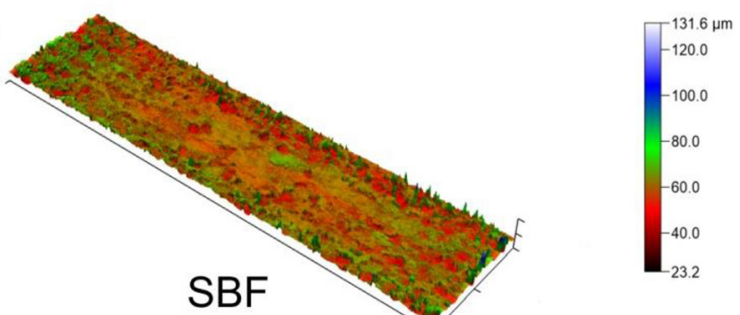

C
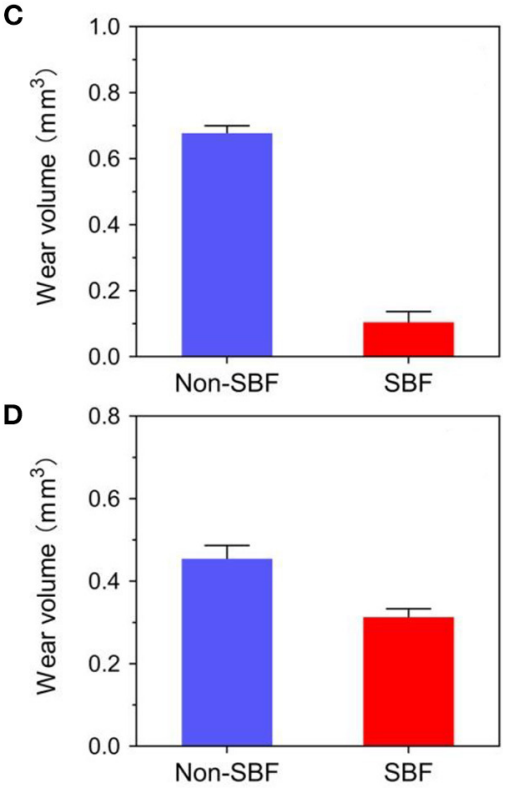

FIGURE 11 | Surface wear morphology observation and wear volume. (A) Surface wear morphology observation of cervical vertebra fixation (CVF) link junction; the color represents the degree of wear. (B) The wear morphology cross-section of cervical disc prosthesis (CDP) link junction. Total wear volume of the (C) CVF link junction and the (D) CDP link junction was quantified.

stress of UHMWPE (28 MPa), the stress distribution of the CSDP error-CDP structure, to some extent, increases the risk of wear, which may affect long-term follow-up results. It has been reported that high-stress distribution in the UHMWPE zone may increase the risk of wear inside the core (Lee et al., 2011, 2016). Therefore, the implantation technology of CSDP is vital, especially the implantation position, which can reduce the wear in the CSDP.

Increased force on facet joints after ADR has been cited as a reason for degenerative changes in implanted segments and poor clinical results; however, biomechanical or clinical evidence has not been clear (Huang et al., 2004; Anderson et al., 2008). In this study, the stress sustained by facet joints increased by $7.3 \%$ in the case of the CSDP FE model, and by 167.9 and $115.9 \%$ in the case of the Prestige LP and CSDP error models, respectively, demonstrating a remarkable stress increase in CADR segments. Chang et al. (2007a) reported that stress increased by $25.1 \%$ under an extension load in comparison with intact segments. Rundell et al. (2008) indicated that stiffness of implanted segments was reduced and ROM increased, while facet joint force varied from 7.7 to $95.3 \mathrm{~N}$ depending on the insertion location. In another study on "ball-and-socket" cervical disc prostheses, Rousseau et al. (2008) suggested that pressure on facet joints may increase from 15 to $86 \%$ by adjusting the center of rotation and that a posterior center of rotation with a large radius was most effective in lowering pressure. Ahn and DiAngelo used a computer simulation model to show that facet-joint force on implanted segments increased during extension from 38.1 to $691 \mathrm{~N}$ in normal segments (Ahn and DiAngelo, 2008). The results of this study indicated that increased pressure on facet joints after CADR might occur with all loads and in various forms and degrees, possibly because of intrinsic design flaws or improper positioning of devices. In conclusion, both CSDP error and Prestige LP FE models might change the force transfer path of motion segments in facet joints.

Similar to other in vitro experiments, biomechanical experiments still need to be verified by in vivo animal experiments, especially in large animals. The comparable kinematics of the lower cervical spine was one of the 


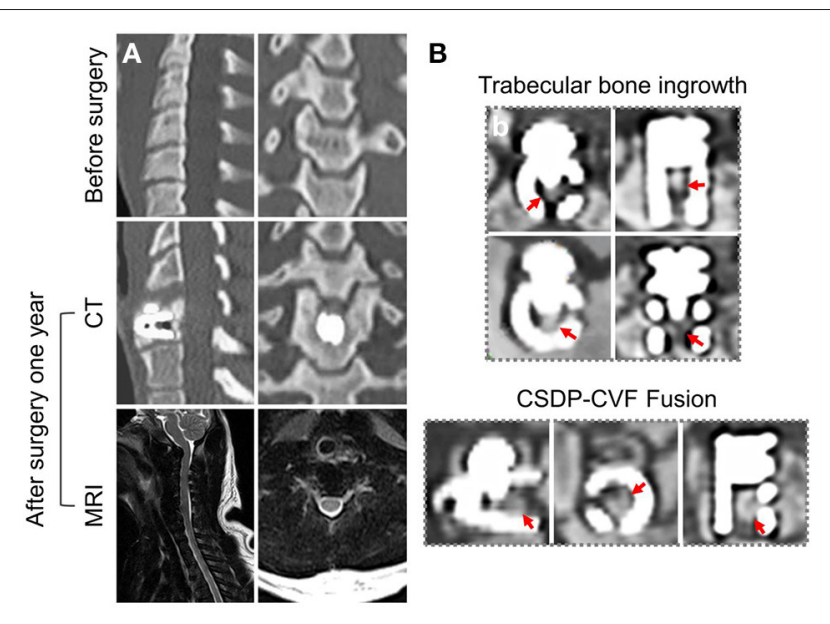

FIGURE 12 | Radiological observation of cervical subtotal discectomy prosthesis (CSDP) in non-human primates. (A) CT and MRI 1 month before and 1 year after CSDP implantation in non-human primates. (B) The trabecular bone grows into the interior of the cervical vertebra fixation (CVF) structure through the tunnel.

criteria used in selecting non-human primates as the animal model for CADR. The upright spine mechanical system of non-human primates is suitable for CADR research. It is absolutely a "worst-case" scenario with regard to evaluating the biomechanics and durability of a cervical prosthesis. Non-human primates are not braced or immobilized after surgery, and they rapidly ambulate and perform their natural gymnastics, trapeze utilization, and cage rocking within the first postoperative week. In this study, human-sized CSDP could not be used in the non-human primates at $\mathrm{C}_{5}-\mathrm{C}_{6}$. The disc space dimensions of non-human primates are more accommodating to the smaller human-sized prosthetic implants; therefore, we adapted the size of CSDP according to nonhuman primate cervical spine anatomy. CT radiographic assessment showed the CSDP remained very stable at the operative level. Based on CT radiographic analysis, there were no incidences of migration or subsidence. Furthermore, the CVF structure fusion phenomenon indicated that the CSDP shows biochemical stability because the implant of surface osseo-integration and vertebral fusion require a stable mechanical condition. There were no significant perioperative complications (i.e., no loosening, no osteolysis, and no translational instabilities).

In this experiment, we aimed to determine CSDP biomechanical patterns of the cervical spine to understand underlying biomechanics and how the CSDP load transfer pattern affected segmental motion. The research has some limitations. First, the FE analysis was computational, and certain assumptions were made during the study. The assumption of the bond upon contact condition for bone and implant is a limitation of this study. The bone-implant interface is much more complex, with relative motions and separations, such as that of CDP-structure bone. However, an appropriately validated model can still provide comparative results to guide orthopedic surgery. The implantation experiment using the CSDP in non-human primates also verified its biomechanical stability. Second, the experimental period of CSDP implantation in non-human primates was short. CADR complications often take a long time to appear. Third, the friction-wear test simplifies the experimental conditions, such as friction movement and loading conditions. Simplified friction movement and loading conditions may not completely reflect the actual wear process of CSDP in the body. Despite these limitations, this research still provides sufficient information to understand more about CSDP biomechanics.

\section{CONCLUSION}

This research has deepened the understanding of how the CSDP affects implant segmental motion as well as stress distribution in the bone-implant interface. Overall, it helps to understand the possible mechanism for the failures and how CSDP designs predispose to the problem. In the FE analysis, compared with those of the Prestige LP FE model, the biomechanical parameters of the CSDP FE model were relatively close to those of the intact FE cervical spine model. The CSDP error FE models proved that the performance of the CSDP, namely, ROM, bone-implant interface stress, and facetjoint force, is affected by the implantation position. In addition, we conducted friction-wear tests on the CSDP based on the results of the FE analysis to understand its degree of durability. Finally, the CSDP had satisfactory performance in non-human primate experiments.

\section{DATA AVAILABILITY STATEMENT}

The original contributions presented in the study are included in the article/supplementary material, further inquiries can be directed to the corresponding author/s.

\section{ETHICS STATEMENT}

The animal study was reviewed and approved by Huazhen Biotechnology, Guangzhou, China.

\section{AUTHOR CONTRIBUTIONS}

ZLi, GS, and YH designed the experiments. JWo, ZLv, and JWa performed the research. YL assisted with the $\mathrm{FE}$ models and data analysis. $\mathrm{KS}$ and $\mathrm{HZ}$ contributed to animal study design. JWo and JWa prepared the manuscript. ZLi and GS revised the manuscript. All authors contributed to the article and approved the submitted version.

\section{FUNDING}

This work was supported by the National Natural Science Foundation of China (No. 31970862), the Natural Science 
Foundation of Guangdong Province (Nos. 2018A030313576, 2019A1515011335), the Science and Technology Program of Guangzhou (No. 201803010001), and the Medical Research Project of Foshan Municipal Health Bureau (No. 20210072).

\section{REFERENCES}

Ahn, H. S., and DiAngelo, D. J. (2008). A biomechanical study of artificial cervical discs using computer simulation. Spine 33, 883-892. doi: 10.1097/BRS.0b013e31816b1f5c

Anderson, P. A., and Rouleau, J. P. (2004). Intervertebral disc arthroplasty. Spine 29, 2779-2786. doi: 10.1097/01.brs.0000146460.11591.8a

Anderson, P. A., Sasso, R. C., and Riew, K. D. (2008). Comparison of adverse events between the Bryan artificial cervical disc and anterior cervical arthrodesis. Spine 33, 1305-1312. doi: 10.1097/BRS.0b013e31817329a1

Bertagnoli, R., Zigler, J., Karg, A., and Voigt, S. (2005). Complications and strategies for revision surgery in total disc replacement. Orthop. Clin. N. Am. 36, 389-395. doi: 10.1016/j.ocl.2005.03.003

Carrier, C. S., Bono, C. M., and Lebl, D. R. (2013). Evidence-based analysis of adjacent segment degeneration and disease after ACDF: a systematic review. Spine J. 13, 1370-1378. doi: 10.1016/j.spinee.2013.05.050

Chang, U. K., Kim, D. H., Lee, M. C., Willenberg, R., Kim, S. H., and Lim, J. (2007a). Changes in adjacent-level disc pressure and facet joint force after cervical arthroplasty compared with cervical discectomy and fusion. J. Neurosurg. Spine 7, 33-39. doi: 10.3171/SPI-07/07/033

Chang, U. K., Kim, D. H., Lee, M. C., Willenberg, R., Kim, S. H., and Lim, J. (2007b). Range of motion change after cervical arthroplasty with ProDisc-C and Prestige artificial discs compared with anterior cervical discectomy and fusion. J Neurosurg. Spine 7, 40-46. doi: 10.3171/SPI-07/07/040

Choi, H., Purushothaman, Y., Baisden, J., and Yoganandan, N. (2020). Unique biomechanical signatures of Bryan, Prodisc C, and Prestige LP cervical disc replacements: a finite element modelling study. Eur. Spine J. 29, 2631-2639. doi: 10.1007/s00586-019-06113-y

Clausen, J. D., Goel, V. K., Traynelis, V. C., and Scifert, J. (1997). Uncinate processes and Luschka joints influence the biomechanics of the cervical spine: quantification using a finite element model of the C5-C6 segment. J. Orthop. Res. 15, 342-347. doi: 10.1002/jor.1100150305

Di Martino, A., Papalia, R., Albo, E., Cortesi, L., Denaro, L., and Denaro, V. (2015). Cervical spine alignment in disc arthroplasty: should we change our perspective? Eur. Spine J. 24, S810-S825. doi: 10.1007/s00586-015-4258-6

Dmitriev, A. E., Cunningham, B. W., Hu, N., Sell, G., Vigna, F., and McAfee, P. C. (2005). Adjacent level intradiscal pressure and segmental kinematics following a cervical total disc arthroplasty: an in vitro human cadaveric model. Spine 30, 1165-1172. doi: 10.1097/01.brs.0000162441.23824.95

Faizan, A., Goel, V. K., Garfin, S. R., Bono, C. M., Serhan, H., Biyani, A., et al. (2012). Do design variations in the artificial disc influence cervical spine biomechanics? A finite element investigation. Eur. Spine J. 21, S653-S662. doi: 10.1007/s00586-009-1211-6

Gandhi, A. A., Kode, S., DeVries, N. A., Grosland, N. M., Smucker, J. D., and Fredericks, D. C. (2015). Biomechanical analysis of cervical disc replacement and fusion using single level, two level, and hybrid constructs. Spine 40, 1578-1585. doi: 10.1097/BRS.0000000000001044

Hilibrand, A. S., and Robbins, M. (2004). Adjacent segment degeneration and adjacent segment disease: the consequences of spinal fusion? Spine J. 4, 190S-194S. doi: 10.1016/j.spinee.2004.07.007

Holmes, A., Wang, C., Han, Z. H., and Dang, G. T. (1994). The range and nature of flexion extension motion in the cervical-spine. Spine 19, 2505-2510. doi: 10.1097/00007632-199411001-00003

Huang, R. C., Lim, M. R., Girardi, F. P., and Cammisa, F. P. (2004). The prevalence of contraindications to total disc replacement in a cohort of lumbar surgical patients. Spine 29, 2538-2541. doi: 10.1097/01.brs.0000144829.57885.20

Kowalczyk, I., Lazaro, B. C. R., Fink, M., Rabin, D., and Duggal, N. (2011). Analysis of in vivo kinematics of 3 different cervical devices: Bryan

\section{ACKNOWLEDGMENTS}

The authors wish to thank Shishu Huang for critical comments, and Ms. Charron of Yale University for revising and editing the manuscript.

disc, ProDisc-C, and Prestige LP disc. J. Neurosurg. Spine 15, 630-635. doi: 10.3171/2011.8.SPINE11273

Kubo, S., Goel, V. K., Yang, S. J., and Tajima, N. (2003). Biomechanical evaluation of cervical double-door laminoplasty using hydroxyapatite spacer. Spine 28, 227-234. doi: 10.1097/01.BRS.0000042246.09816.20

Lai, H., Goto, S., Yamagata, M., Tamaki, T., Moriya, H., Takahashi, K., et al. (1994). Three-dimensional motion of the upper cervical spine in rheumatoid arthritis. Spine 19, 272-276. doi: 10.1097/00007632-199402000-00004

Lazaro, B. C. R., Yucesoy, K., Yuksel, K. Z., Kowalczyk, I., Rabin, D., Fink, M., et al. (2010). Effect of arthroplasty design on cervical spine kinematics: analysis of the Bryan Disc, ProDisc-C, and Synergy Disc. Neurosurg. Focus 28:E6. doi: 10.3171/2010.3.FOCUS1058

Lee, J. H., Park, W. M., Kim, Y. H., and Jahng, T. A. (2016). A biomechanical analysis of an artificial disc with a shock-absorbing core property by using whole-cervical spine finite element analysis. Spine 41, E893-E901. doi: 10.1097/BRS.0000000000001468

Lee, S. H., Im, Y. J., Kim, K. T., Kim, Y. H., Park, W. M., and Kim, K. (2011). Comparison of cervical spine biomechanics after fixed- and mobilecore artificial disc replacement: a finite element analysis. Spine 36, 700-708. doi: 10.1097/BRS.0b013e3181f5cb87

Lin, C. Y., Kang, H., Rouleau, J. P., Hollister, S. J., and La Marca, F. (2009). Stress analysis of the interface between cervical vertebrae end plates and the Bryan, Prestige LP, and ProDisc-C cervical disc prostheses an in vivo image-based finite element study. Spine 34, 1554-1560. doi: 10.1097/BRS.0b013e3181aa643b

Matge, G., Berthold, C., Gunness, V. R. N., Hana, A., and Hertel, F. (2015). Stabilization with the Dynamic Cervical Implant: a novel treatment approach following cervical discectomy and decompression. J. Neurosurg. Spine 22, 237-245. doi: 10.3171/2014.10.SPINE131089

Mimura, M., Moriya, H., Watanabe, T., Takahashi, K., Yamagata, M., and Tamaki, T. (1989). Three-dimensional motion analysis of the cervical spine with special reference to the axial rotation. Spine 14, 1135-1139. doi: 10.1097/00007632-198911000-00001

Mo, Z. J., Zhao, Y. B., Du, C. F., Sun, Y., Zhang, M., and Fan, Y. B. (2015). Does location of rotation center in artificial disc affect cervical biomechanics? Spine 40, E469-E475. doi: 10.1097/BRS.0000000000000818

Moroney, S. P., Schultz, A. B., Miller, J. A., and Andersson, G. B. (1988). Loaddisplacement properties of lower cervical spine motion segments. J. Biomech. 21, 769-779. doi: 10.1016/0021-9290(88)90285-0

Ng, H. W., Teo, E. C., and Zhang, Q. H. (2004). Biomechanical effects of C2C7 intersegmental stability due to laminectomy with unilateral and bilateral facetectomy. Spine 29, 1737-1745. doi: 10.1097/01.BRS.0000134574.36487.EB

Nunley, P. D., Coric, D., Frank, K. A., and Stone, M. B. (2018). Cervical disc arthroplasty: current evidence and real-world application. Neurosurgery 83, 1087-1106. doi: 10.1093/neuros/nyx579

Pandey, P. K., Pawar, I., Gupta, J., and Verma, R. R. (2017). Comparison of outcomes of single-level anterior cervical discectomy with fusion and singlelevel artificial cervical disc replacement for single-level cervical degenerative disc disease. Spine 42, E41-E49. doi: 10.1097/BRS.0000000000001696

Panjabi, M. M., Crisco, J. J., Vasavada, A., Oda, T., Cholewicki, J., Nibu, K., et al. (2001). Mechanical properties of the human cervical spine as shown by three-dimensional load-displacement curves. Spine 26, 2692-2700. doi: 10.1097/00007632-200112150-00012

Panjabi, M. M., Summers, D. J., Pelker, R. R., Videman, T., Friedlaender, G. E., and Southwick, W. O. (1986). Three-dimensional load-displacement curves due to forces on the cervical spine. J. Orthop. Res. 4, 152-161. doi: 10.1002/jor.1100040203

Pelker, R. R., Duranceau, J. S., and Panjabi, M. M. (1991). Cervical spine stabilization. A three-dimensional, biomechanical evaluation of 
rotational stability, strength, and failure mechanisms. Spine 16, 117-122. doi: 10.1097/00007632-199116020-00003

Penning, L. (1978). Normal movements of the cervical spine. Am. J. Roentgenol. 130, 317-326. doi: 10.2214/ajr.130.2.317

Penning, L., and Wilmink, J. T. (1987). Rotation of the cervical spine. A CT study in normal subjects. Spine 12, 732-738. doi: 10.1097/00007632-198710000-00003

Rousseau, M. A., Bonnet, X., and Skalli, W. (2008). Influence of the geometry of a ball-and-socket intervertebral prosthesis at the cervical spine - a finite element study. Spine 33, E10-E14. doi: 10.1097/BRS.0b013e31815e62ea

Rundell, S. A., Auerbach, J. D., Balderston, R. A., and Kurtz, S. M. (2008). Total Disc replacement positioning affects facet contact forces and vertebral body strains. Spine 33, 2510-2517. doi: 10.1097/BRS.0b013e31818 $6 \mathrm{~b} 258$

Sasso, R. C., Anderson, P. A., Riew, K. D., and Heller, J. G. (2011). Results of cervical arthroplasty compared with anterior discectomy and fusion: four-year clinical outcomes in a prospective, randomized controlled trial. J. Bone Joint Surg. 93, 1684-1692. doi: 10.2106/JBJS.J.00476

Thaler, M., Hartmann, S., Gstottner, M., Lechner, R., Gabl, M., and Bach, C. (2013). Footprint mismatch in total cervical disc arthroplasty. Eur. Spine J. 22, 759-765. doi: 10.1007/s00586-012-2594-3

Weinans, H., Huiskes, R., and Grootenboer, H. J. (1993). Quantitative analysis of bone reactions to relative motions at implant-bone interfaces. J. Biomech. 26, 1271-1281. doi: 10.1016/0021-9290(93)90351-E
Yu, C. C., Liu, P., Huang, D. G., Jiang, Y. H., Feng, H., and Hao, D. J. (2016). A new cervical artificial disc prosthesis based on physiological curvature of end plate: a finite element analysis. Spine J. 16, 1384-1391. doi: 10.1016/j.spinee.2016.06.019

Zhang, Q. H., Teo, E. C., Ng, H. W., and Lee, V. S. (2006). Finite element analysis of moment-rotation relationships for human cervical spine. J. Biomech. 39, 189-193. doi: 10.1016/j.jbiomech.2004.10.029

Zhong, Z. M., Zhu, S. Y., Zhuang, J. S., Wu, Q., and Chen, J. T. (2016). Reoperation after cervical disc arthroplasty versus anterior cervical discectomy and fusion: a meta-analysis. Clin. Orthop. Relat. R. 474, 1307-1316. doi: 10.1007/s11999-016-4707-5

Conflict of Interest: The authors declare that the research was conducted in the absence of any commercial or financial relationships that could be construed as a potential conflict of interest.

Copyright (c) 2021 Wo, Lv, Wang, Shen, Zhu, Liu, Huang, Sun and Li. This is an open-access article distributed under the terms of the Creative Commons Attribution License (CC BY). The use, distribution or reproduction in other forums is permitted, provided the original author(s) and the copyright owner(s) are credited and that the original publication in this journal is cited, in accordance with accepted academic practice. No use, distribution or reproduction is permitted which does not comply with these terms. 